\title{
Thoracic endovascular aortic repair for traumatic aortic injuries insight from literature and practical recommendations
}

\author{
Ilenia D'ALESSIO 1, Maurizio DOMANIN 1,2 *, Daniele BISSACCO ${ }^{1}$, Pierantonio RIMOLDI ${ }^{3}$, \\ Bruno PALMIERI ${ }^{3}$, Gabriele PIFFARETTI ${ }^{4}$, Santi TRIMARCHI 1,2
}

${ }^{1}$ Unit of Vascular Surgery, Foundation IRCCS Ca' Granda Ospedale Maggiore Policlinico, Milan, Italy; ${ }^{2}$ Department of Clinical Sciences and Community Health, University of Milan, Milan, Italy; 3Department of Cardio-Thoraco-Vascular, ASST Grande Ospedale Metropolitano Niguarda, Milan, Italy; ${ }^{4}$ Unit of Vascular Surgery, Department of Medicine and Surgery, University of Insubria School of Medicine, Varese, Italy

*Corresponding author: Maurizio Domanin, Unit of Vascular Surgery, Foundation IRCCS Ca' Granda Ospedale Maggiore Policlinico, Via Francesco Sforza 35, 20122 Milan, Italy. E-mail: maurizio.domanin@unimi.it

AB ST R A C T

INTRODUCTION: Thoracic endovascular aortic repair (TEVAR) for treatment of blunt traumatic aortic injuries (BTAIs) is nowadays the gold standard technique in adult patients, replacing gradually the use of open repair (OR). Although randomized controlled trials will never be performed comparing TEVAR to OR for BTAIs invasive management, trauma and vascular societies guidelines today primarily recommend the former for BTAI patients with a suitable anatomy. The aim of this review was to describe past and recent data published in literature regarding pros and cons of TEVAR treatment in BTAI, and to analyze some debated issues and future perspectives.

EVIDENCE ACQUISITION: Preferred Reporting Items for Systematic Reviews and Meta-Analyses (PRISMA) guidelines and Scale for the Assessment of Narrative Review Articles (SANRA) were used to obtain and describe selected articles on TEVAR in BTAI.

EVIDENCE SYNTHESIS: Young ( $<50$ years) men were the most operated population. The use of TEVAR increased over the years, with a progressive reduction in mortality and overall postoperative complication rates when compared with OR. Lack of information remain about the percentage of urgent cases.

CONCLUSIONS: TEVAR is considered nowadays the treatment of choice in BTAI patients. In case of aortic rupture (grade IV) the treatment is mandatory, while intimal tear (grade I) and intramural hematoma (grade II) can be safely managed with no operative management (NOM). Debate is still ongoing on grade III (pseudoaneurysms). Unfortunately, several aspects remain not yet clarified, including disease classification, type and grade to treat, timing (urgent versus elective), priority of vascular injuries in polytrauma patients, and TEVAR use in pediatrics and young patients.

(Cite this article as: D'Alessio I, Domanin M, Bissacco D, Rimoldi P, Palmieri B, Piffaretti G, et al. Thoracic endovascular aortic repair for traumatic aortic injuries insight from literature and practical recommendations. J Cardiovasc Surg 2020;61:000-000. DOI: 10.23736/S0021-9509.20.11580-5)

KEY WORDS: Aorta; Wounds and injuries; Systematic review.

\section{Introduction}

B lunt traumatic aortic injury (BTAI) is a life-threatening lesion that usually occurs at the aortic isthmus, just distal to the left subclavian artery, although other vascular sites can be affected. The first document that describes a case of BTAI was reported in 1557 by Andreas Vesalius, regarding a patient deceased after a fall from its horse. ${ }^{1}$ At the beginning of vascular surgery as an independent disci- pline, two of the larger series were reported by Kuhn and Strassmann the former reviewed the literature of 75 cases published from 1895 to $1925,{ }^{2}$ while the latter described his personal series of 72 cases. ${ }^{3}$ Patients who survived an aortic rupture, including those who developed post-traumatic aortic aneurysms, have been less frequently reported in literature over the decades. The natural history of BTAI was appreciated after the study of Parmley et al. who collected and analyzed 296 patients. ${ }^{4}$ BTAI was associated 
with a high mortality rate and has been implicated as the second most common cause of death in trauma patients, behind only intracranial hemorrhage. ${ }^{4,5}$ Nowadays, the incidence of traumatic aortic lesion is estimated between 1.5-2 of patients who had blunt thoracic trauma ${ }^{6-9}$ Fabian et al. suggested that after a BTAI, less than 25 of patients survive after hospital admission ${ }^{10}$ and, among those, up to 50 die within 24 hours. Burkhart et al. in an analysis of 242 autopsies with BTAI reported that 57 were dead on the spot or arriving to the emergency room, 37 died within the first 4 hours and 6 died after. ${ }^{11}$ In recent years, endovascular thoracic aortic repair (TEVAR) has been increasingly adopted to treat BTAI patients. It consists in the placement of modular graft components that are delivered via the iliac or femoral arteries to the site of lesion, avoiding thoracotomy and cardiac bypass. Compared to open repair (OR), TEVAR has been proven to be effective as a minimally invasive, quicker and safe technique, no requiring systemic heparinization. These improvements are important advantages in BTAI patients, particularly in case of polytraumatized ones. ${ }^{10,12-15}$ Despite better short and longterm results using TEVAR, several perioperative and postoperative topics still remain unclear, particularly in terms of indications to endovascular repair and timing. The aim of this review was to describe available data in published peer-review scientific literature on the use of TEVAR in BTAI patients, describing current missing or consolidated evidences, recommendations and clinical experiences.

\section{Evidence acquisition}

An articles search method and presentation were performed according to the Scale for the Assessment of Narrative Review Articles (SANRA), a six-items scale developed for the quality assessment of narrative review articles. ${ }^{16}$ Despite SANRA was usually used during the peer-review process, Authors tried to obtain the maximum score possible (12 points) in order to improving the quality of manuscript. For this purpose, authors used SANRA during the article prewriting planning, adopting recommendations provided by instructions document. ${ }^{17}$ Furthermore, recommendations from Green et al. were also adopted. ${ }^{18}$ To article research process, recommendations of Preferred Reporting Items for Systematic Reviews and Meta-Analyses (PRISMA) guidelines were also adopted. ${ }^{19}$

\section{Search strategy}

The research was conducted on Medline (PubMed), Embase and The Cochrane Library between January 1, 1990 and May 31, 2020 (30 years), among articles published in English language. There were no limitations on study type applied to the search. A first search was performed in March 2020, and an updated was performed in May 2020. Keywords were selected using medical subject headings (MeSH) for Medline and The Cochrane Library and the EMTREE terms for Embase. Keywords as "aortic trauma," "blunt trauma," "TEVAR," "mortality," "follow up" and "follow-up studies" were combined to obtain the first publications cluster. For terms "mortality," "TEVAR" and "follow-up studies" only MeSH terms modality was used in order to avoid confusing redundant results, as well as for the term "follow up" for the Embase research step. To connect terms with each other the Boolean operators "AND" and "OR" were used. The peer-review journals Annals of Vascular Surgery, Annals of Thoracic surgery, Journal of Cardiac Surgery, Journal of Cardiovascular Surgery, European Journal of Vascular and Endovascular Surgery, Journal of Endovascular Therapy, Journal of Trauma, European Journal of Cardio-thoracic Surgery, Journal of Vascular Surgery, American Journal of Surgery, and Circulation were queried on May 29, 2020 in order to find articles published "online first" and not yet indexed on scientific online database. All titles and abstracts of potentially useful articles were selected. Two researchers (ID and MD) independently screened titles, abstracts and full text of search results. Data from all included studies were then independently extracted. In case of discrepancies in article or data extraction, a third research (DB) was consulted to raise the final consensus. References of all identified relevant studies were used to perform a recursive search of the literature. Metalib ${ }^{\circledR}$ (University of Milan, Milan, Italy), SBBL (Lombard Biomedical Librarian System) and personal journal subscription were used to obtain full text articles in case of eligible titles and abstracts.

\section{Inclusion and exclusion criteria}

Articles presenting the use of TEVAR for BTAIs were primarily included. We excluded from the analysis articles that investigate the role of TEVAR only for the treatment of chronic aortic lesions; abstract and/or case report or case series with less than 60 patients; studies that did not provide acceptable outcomes analysis (e.g. complications rate, mortality rate, etc.); studies focused only on open repair or non-operative management (NOM); company sponsored trials. Conversely, studies on both urgent and delayed treatment were considered eligible, as well as studies with mixed cohorts of patients treated with TEVAR and OR, if matching with inclusion criteria. 


\section{Evidence synthesis}

Combining filters as mentioned, 3022 articles were found (2240 from PubMed, 777 from Embase, 5 from Cochrane Library). Among these, 2415 studies were excluded because duplicates or with title and/or abstracts not match with the topic. The remaining 607 articles underwent a second selection, depending on abstract information (Figure 1). After abstract analysis, 11 articles were finally adopted as final article cluster, and describe below (Table I). ${ }^{15}, 20-29$ Number of patients vary consistently, from 6325 to $3628^{26}$ In the majority of cases were cohort comparative studies between TEVAR and OR. In all selected studies, TEVAR and OR groups experienced similar preoperative injury severity score (ISS). Furthermore, young $(<50$ years) men were the most representative in patients' cohort. Only 4 studies $21,25,27,29$ provided percentage of patients operated in an urgent setting. No differences were described in terms of age between TEVAR and OR. Most common postoperative complications in TEVAR cohorts were spinal cord complications (ranging from 0 to 12.5), acute kidney in-

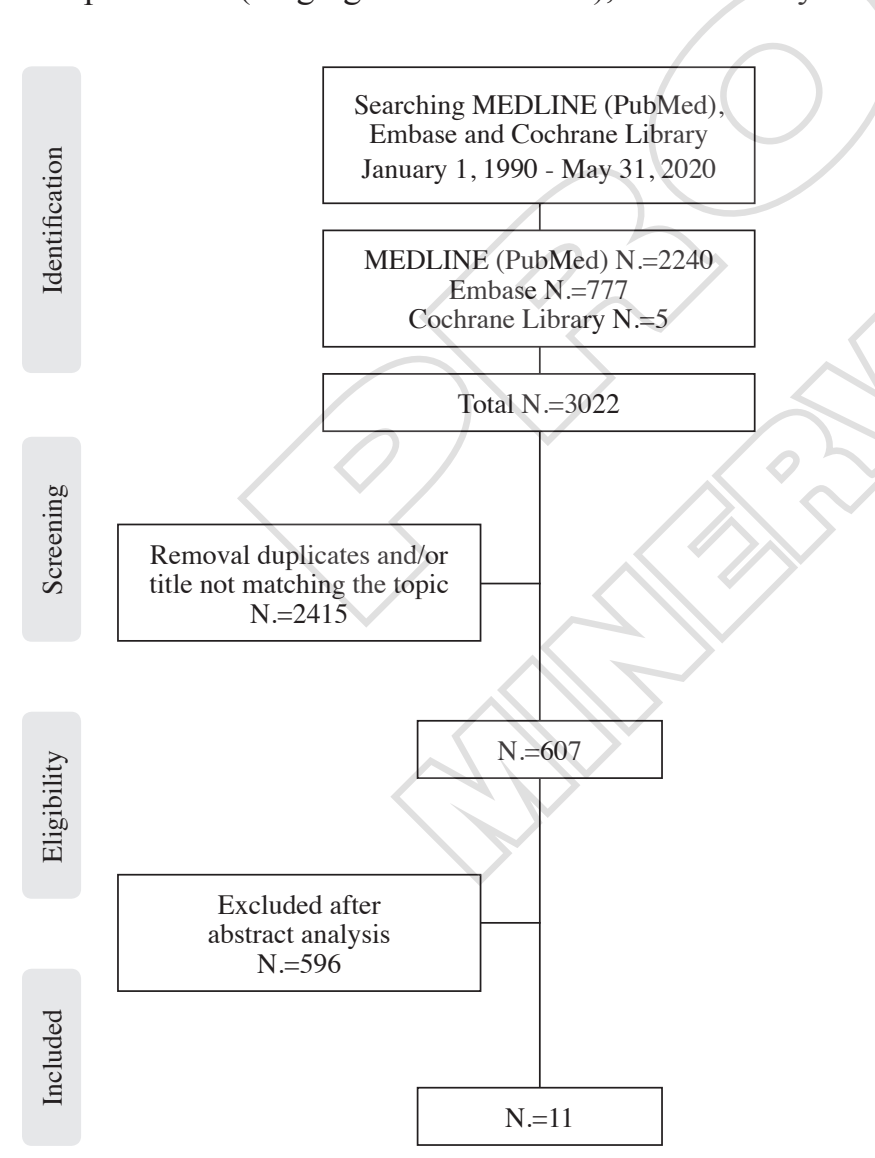

Figure 1.-Flowchart of literature search. jury (from 0 to 8.3 ), acute respiratory distress syndrome and pulmonary complications (from 10.6 to 28.5), cardiac complications (from 0.7 to 2.9 ). Important heterogeneity in complication definitions were identified among articles, leading to mismatch and difficulties in study comparison. Surprisingly, very few data were obtained in terms of injury grade (according to SVS or other classifications).

\section{Discussion}

\section{Incidence and prognosis of BTAI}

It is quite possible that the real incidence of BTAI is strongly underestimated. Chiara et al. studying 199 consecutive autopsies, found out that BTAI was present in 53/199 cases (26.6) and that it was the cause of death in 60 of them. ${ }^{30}$ In a multicenter study involving 274 cases of blunt aortic injury, 81 percent were caused by automobile collisions. ${ }^{10}$ Other etiologies of blunt thoracic aortic injury include motorcycle and aircraft crashes, automobile versus pedestrian accidents, falls, and crush injury. ${ }^{5}$ Approximately 70 percent of victims are male. ${ }^{31}$ Forty percent of patients with BTAI have numerous injuries associated cardiac lesions, rib fractures, hemothoraces, and intra-abdominal injuries. ${ }^{5}$ A further confirmation of the overall seriousness of polytraumatized patients, are the high values of ISS, the most commonly used scoring system for trauma assessment and benchmarking, that usually result $>40$ in case of BTAI. ${ }^{32}$ For many years, open repair has been the gold standard technique for traumatic aortic lesions. Historically, the first TEVAR for BTAI was performed in 1997 by Kato et al. ${ }^{33}$ Since then, TEVAR has gained exponentially in popularity among vascular surgeons as a first line of management in the treatment of BTAI. In a review from the Eastern Association for the Surgery of Trauma (EAST) that included 37 nonrandomized studies, the risk of death was significantly reduced for endovascular compared with open surgical repair (RR $0.49,95$ CI 0.36-0.66), as well as the risk for paraplegia (RR 0.34, 95 CI 0.17-0.69). ${ }^{34}$

Furthermore, TEVAR consents a faster recovery and allows a quicker return to work, both being important aspects in the working-age and working-class population. ${ }^{35}$ At early 2000's literature on BTAI started to increase, thanks to the many advantages offered by TEVAR in terms of better patient's survival rate. Consequently, the Society of Vascular Surgery (SVS) guidelines for the management of BTAI were updated introducing TEVAR as first line treatment. Despite the progress of techniques and devices, there remains need for further studies regarding mid and long-term graft-related complications. 
TABLE I.-Summary of results regarding the selected studies.

\begin{tabular}{|c|c|c|c|c|c|c|c|c|c|c|}
\hline Author & Year & $\begin{array}{l}\text { Total number } \\
\text { of patients } \\
\text { (N.) }\end{array}$ & $\begin{array}{l}\text { Urgent repair } \\
(<24 \mathrm{~h}) \\
(\%)\end{array}$ & $\begin{array}{l}\text { ISS } \\
\text { (OR) }\end{array}$ & $\begin{array}{c}\text { ISS } \\
\text { (TEVAR) }\end{array}$ & $\begin{array}{l}\mathrm{OR} \\
\text { (N.) }\end{array}$ & $\begin{array}{l}\text { TEVAR } \\
\text { (N.) }\end{array}$ & $\begin{array}{c}\text { Mean age or } \\
\text { (ys) }\end{array}$ & $\begin{array}{c}\text { Mean age } \\
\text { TEVAR } \\
\text { (ys) }\end{array}$ & $\begin{array}{l}\text { Overall and major complication OR } \\
\qquad(\%)\end{array}$ \\
\hline Demetriades ${ }^{15}$ & 2008 & 193 & N/A & 39 & 39 & 68 & 125 & 34.1 & 42.2 & $\begin{array}{l}\text { Overall } 50 \\
\text { Paraplegia } 2.9 \\
\text { AKI } 10.4 \\
\text { ARDS } 18.2\end{array}$ \\
\hline Chung20 & 2008 & 103 & N/A & 37 & 35 & 36 & 26 & 37 & 46 & $\begin{array}{l}\text { Overall N/A } \\
\text { Paraplegia } 15.6 \\
\text { Paraparesis } 9.4 \\
\text { AKI 3.1 } \\
\text { Graft failure } 0 \\
\text { Left arm ischemia } 0\end{array}$ \\
\hline Estrera $^{21}$ & 2010 & 145 & $\begin{array}{c}73.45 \text { (OR) } \\
10 \text { (TEVAR) }\end{array}$ & 41 & 37 & 113 & 32 & & 45 & $\begin{array}{l}\text { Overall N/A } \\
\text { Paraplegia } 2.6 \\
\text { Stroke } 0.8\end{array}$ \\
\hline Jonker 22 & 2010 & 328 & $\begin{array}{c}98.8 \text { (OR) } \\
95.5 \text { (TEVAR) }\end{array}$ & N/A & N/A & & & & 41.6 & $\begin{array}{l}\text { Overall N/A } \\
\text { Cardiac } 5.4\end{array}$ \\
\hline Riesenman $^{23}$ & 2012 & 100 & N/A & & & & & & & $\begin{array}{l}\text { Overall N/A } \\
\text { AKI } 31 \\
\text { Paralysis/paraparesis } 6 \\
\text { MOF } 14\end{array}$ \\
\hline Azizzadeh ${ }^{24}$ & 2013 & 106 & & & & & 50 & & 41 & $\begin{array}{l}\text { Overall } 69.6 \text { (including in- } \\
\text { hospital death) } \\
\text { Cardiac } 8.9 \\
\text { Pulmonary } 57.1 \\
\text { Paraplegia } 0 \\
\text { AKI } 17.8\end{array}$ \\
\hline Chen 25 & 2015 & 63 & (C) & 40 & 41 & & & 37.4 & 38.2 & $\begin{array}{l}\text { Overall N/A } \\
\text { Stroke } 8.6 \\
\text { AKI } 17.4\end{array}$ \\
\hline Grigorian ${ }^{26}$ & 2018 & & & & & & 3226 & 39.3 & 42.5 & $\begin{array}{l}\text { Overall N/A } \\
\text { Paraplegia } 0 \\
\text { AKI } 9 \\
\text { ARDS } 14.8 \\
\text { Cardiac } 0.4\end{array}$ \\
\hline Calvo $^{27}$ & 2018 & $\begin{array}{c}336 \\
\text { (on 2159 } \\
\text { all-grade BTAI) }\end{array}$ & $81.3(\mathrm{O}$ & +4 & N/A & 80 & 256 & 52 & 46.8 & $\begin{array}{l}\text { Overall N/A } \\
\text { Cardiac } 8.8 \\
\text { Pulmonary } 30 \\
\text { AKI } 31.3 \\
\text { Spinal cord complications } 3.5 \\
\text { Neurological complications } 21.3\end{array}$ \\
\hline Elkbuli $^{28}$ & 2019 & 275 & N/A & 35 & 36 & 103 & 172 & 36 & 41 & $\begin{array}{l}\text { Overall N/A } \\
\text { AKI } 8.7\end{array}$ \\
\hline Alarhayem ${ }^{29}$ & 2020 & 3042 & 75 & N/A & 32 & N/A & 2821 & N/A & 42 & $\begin{array}{l}\text { Overall N/A } \\
\text { Major N/A }\end{array}$ \\
\hline
\end{tabular}

IIS: Injury severity score; OR: open repair; AKI: acute kidney injury; ARDS: acute respiratory distress syndrome; MOF: multi-organ failure; LOS: length of stay; BTAI: blunt thoracic aortic trauma.

\section{The evolution of classifications}

Treatment options for BTAIs are strictly related to the degree of the lesion. For this reason, the knowledge of grad- ing systems is fundamental for each vascular surgeon. The first classification was proposed in 1958 by Parmley who divided the severity of aortic lesion based on the injured layers of the aortic wall. ${ }^{4}$ 


\begin{tabular}{|c|c|c|c|}
\hline $\begin{array}{l}\text { Overall and major } \\
\text { complication TEVAR } \\
(\%)\end{array}$ & $\begin{array}{l}\text { Mortality OR } \\
(\%)\end{array}$ & $\begin{array}{l}\text { Mortality TEVAR } \\
(\%)\end{array}$ & Conclusions \\
\hline $\begin{array}{l}\text { Overall } 42.4 \\
\text { Paraplegia } 0.8 \\
\text { AKI } 8.3 \\
\text { ARDS } 13.9 \\
\text { Graft complication } 18.4\end{array}$ & 23.5 & 7.2 & $\begin{array}{l}\text { TEVAR is associated with lower mortality and fewer blood transfusions, } \\
\text { but there is a considerable risk of device-related complications }\end{array}$ \\
\hline $\begin{array}{l}\text { Overall N/A } \\
\text { Paraplegia } 0 \\
\text { Paraparesis } 0 \\
\text { AKI } 0 \\
\text { Graft failure } 0 \\
\text { Left arm ischemia } 11.8\end{array}$ & 11.1 & 7.7 & $\begin{array}{l}\text { TEVAR is associated with lower perioperative mortality and morbidity rates } \\
\text { than OR }\end{array}$ \\
\hline $\begin{array}{l}\text { Overall N/A } \\
\text { Paraplegia } 0 \\
\text { Stroke } 3\end{array}$ & 20 & 0 & omes with delayed selective management and TEVAR \\
\hline $\begin{array}{l}\text { Overall N/A } \\
\text { Cardiac } 2.9 \\
\text { Stroke } 2.9 \\
\text { Pulmonary } 23.9 \\
\text { Paraplegia } 0 \\
\text { AKI } 3 \\
\text { Endoleak } 9\end{array}$ & 16.9 & 6 & $\begin{array}{l}\text { TEVAR has lower postoperative mortality pulmonary complications but has } \\
\text { device-related complications }\end{array}$ \\
\hline $\begin{array}{l}\text { Overall N/A } \\
\text { AKI } 4 \\
\text { Paralysis/paraparesis } 0 \\
\text { MOF } 4\end{array}$ & 37 & & rative times, blood loss, and overall hospital mortality \\
\hline $\begin{array}{l}\text { Overall } 48 \text { (including in- } \\
\text { hospital death) } \\
\text { Cardiac } 6 \\
\text { Pulmonary } 36 \\
\text { Paraplegia } 0 \\
\text { AKI } 8\end{array}$ & 8.9 & & $\begin{array}{l}\text { treated with OR had three times higher odds to face a complication } \\
\text { hospital death }\end{array}$ \\
\hline $\begin{array}{l}\text { Overall N/A } \\
\text { Stroke } 0 \\
\text { AKI } 0\end{array}$ & & & $\mathrm{r}$ and safer treatment option respect to OR \\
\hline $\begin{array}{l}\text { Overall N/A } \\
\text { Paraplegia } 0.1 \\
\text { AKI } 5.6 \\
\text { ARDS } 10.6 \\
\text { Cardiac } 0.7\end{array}$ & & & associated with lower mortality, LOS and major complications \\
\hline $\begin{array}{l}\text { Overall N/A } \\
\text { Cardiac } 0.8 \\
\text { Pulmonary } 28.5 \\
\text { AKI } 16 \\
\text { Spinal cord/complications } \\
\text { Neurological complication }\end{array}$ & & & $\begin{array}{l}\text { Mortality is similar for TEVAR and OR, but TEVAR has fewer } \\
\text { complications }\end{array}$ \\
\hline $\begin{array}{l}\text { Overall N/A } \\
\text { AKI } 4.7\end{array}$ & & 11 & TEVAR is superior to OR on injury-adjusted, all-cause mortality \\
\hline $\begin{array}{l}\text { Overall N/A } \\
\text { Major N/A }\end{array}$ & & 8.4 & Delayed repair has improved survival \\
\hline
\end{tabular}

Gavant et al. published the first classification system based on computed tomography angiography (CTA) images in 1999.36 Other groups then published their classification systems with different degree of variation. ${ }^{37-42}$ In
2011, the SVS published the clinical practice guidelines for endovascular repair of BTAI ${ }^{43}$ based on the Azizzadeh's classification (Figure 2):

- grade I: intimal tear; 


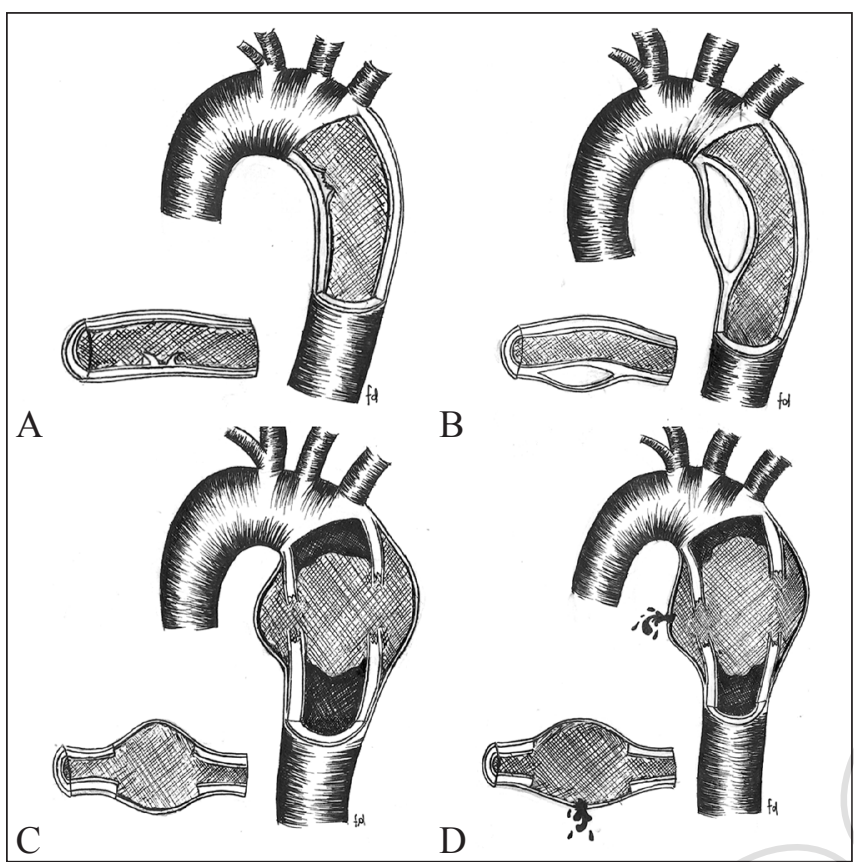

Figure 2.-Society of Vascular Surgery (SVS) classification of blunt thoracic trauma: A) grade I intimal tear; B) grade II intramural hematoma; C) grade III pseudoaneurysm; D) grade IV rupture.

- grade II: intramural hematoma;

- grade III: pseudoaneurysm;

- grade IV: rupture.

This classification does not take into account the assessment of aortic lesion dimensions, as promoted by the Vancouver simplified grading system ${ }^{40}$ or the classification scheme proposed by Starnes et al., based on the presence or absence of abnormalities of the aortic external contour. ${ }^{41}$ Recently, Harborview classification tried to highlight CTA scan image findings, adopting an urgent approach only in case of active extravasation of contrast media out of aortic wall. 44

When do I treat a BTAI? Results according to SVS classification

SVS GRADE I AND II

Currently, the SVS guidelines suggests TEVAR is associated with better survival and decreased risk of complications if compared with OR or NOM, for grade II to IV BTAI. ${ }^{33}$ In its guidelines the European Society for Vascular Surgery (ESVS) suggest that "patients with free rupture of a BTAI or a large peri-aortic hematoma ( $\geq 15 \mathrm{~mm}$ ) should undergo emergency repair while in cases without large hematoma, delayed intervention should be considered to prioritize treatment of associated life threatening injuries." 45 The associated low mortality rates and excellent mid-term outcomes for grade I BTAI, allow to treat them only medically, i.e. with $\beta$-blockage, maintenance of systolic blood pressure between 80 and $90 \mathrm{mmHg}$ and heart rate between 60 and 80 beats/min, serial transesophageal echocardiography (TEE) studies, and invasive monitoring in the intensive care unit (ICU). Anymore, is mandatory to perform an active surveillance with close imaging follow up to detect early any potential adverse evolution. Any inability to perform all these tasks should be considered as a contraindication to NOM. ${ }^{46}$ Nowadays, the increasing use of high-resolution diagnostic medical imaging allows frequent detection of grade I BTAI for which a NOM is more suitable. In consideration of the overall favorable prognosis, in the past these patients have been submitted to unnecessary procedural- and device-related risk and long term complications that have been reported in up to 18.4 of cases. ${ }^{15}$ For all these reasons they have also been sarcastically called VOMIT "victims of modern imaging technology." 47

Fortuna et al. reported no significant differences between patients with grade I and II BTAI managed with NOM if compared to OR or TEVAR. ${ }^{48}$ Sandhu et al. recently reported, in a retrospective study on 48 NOM survived patients that grade I and II BTAI may spontaneously repair within 8 weeks, with excellent results both in terms of immediate and intermediate aortic mortality (0). The only predictors of poor short term outcomes in NOM resulted age $>30$ years and severity of ISS. ${ }^{49}$ Soong et al. in a meta-regression analysis on 35 studies and 2897 patients observed an all-cause in-patients mortality for grade I BTAI and grade II BTAI of 6.8 and 0 , respectively. ${ }^{50}$ Gaffey et al. published their study on the natural history of NOM for grade II BTAI, reporting neither progression of the aortic lesions nor operative interventions performed. They concluded that grade II BTAI can be safely managed with NOM, anyway encouraging blood pressure control, exercise restriction and close immediate and long term follow up by aortic imaging. ${ }^{51}$ Some authors suggest that the management of these cases needs to be shifted toward surgical management only in case of significant worsening detecting during follow-up imaging or when concomitant cerebral injuries require elevation of the cerebral perfusion pressure. 52

\section{SVS GRADE III}

Treatment of grade III BTAI is the most debated and controversial topic in aortic injuries management. Clinical presentation of grade III BTAI is rather heterogeneous. More- 
over, the right timing for surgical management has not been still defined. Some authors reported that in some cases of grade III BTAI selective NOM may be safe. Caffarelli et $a l$. , in case of small pseudoaneurysms (less than half of the aortic circumference), obtained encouraging results with NOM. Moreover, most of the treated patients with NOM resulted still alive many years later when observed at follow up. ${ }^{39}$ Gandhi et al. reported in a comparative study between grade III BTAI treated by TEVAR vs. NOM, 2 (11.8) and 5 (27.8) deaths, respectively, of which only one of the NOM group related to the BTAI $(\mathrm{P}=0.402)$. Follow up CTA then confirmed good long term outcomes with, in most of the cases, the spontaneous resolution of the injuries with related complications rate similar between OR and TEVAR groups. ${ }^{53}$ Kidane et al. compared 28 grade III NOM patients with 31 patients treated by TEVAR. Conversely, mortality rate resulted significantly worst in the NOM cohort (42.8) vs. TEVAR (20.7) $(\mathrm{P}<0.007)$. Between the $12 \mathrm{NOM}$ patients died, exitus occurred in 8 patients (66.0) for other injuries, before any TEVAR attempt. But excluding the patients' mortality occurred during day 0 , the differences between the two cohorts in mortality rates resulted not significant. ${ }^{46}$ Soong et al. in a meta-analysis on 35 studies, which comprised 2897 cases, reported in grade III an all-cause mortality rate of 29.2.50 Short-term survival rate resulted more influenced by extravascular factors, such as multiorgan failure or respiratory insufficiency, rather than the BTAI grade. Fortuna et al. focusing their analysis on the presentation imaging of grade III BTAI, were unable to identify any independent predictors of aortic related mortality. 48 The seyerity of radiological imaging variables (e.g. mediastinal hematoma dimensions and lesion/normal aortic diameter ratio) were not harbingers of aortic related mortality. In conclusion, the main variable that precluded OR or TEVAR treatment in grade III BTAI resulted more related to the pattern of comorbidities rather than by the radiological findings. 48 Harris et al. reported that small pseudoaneurysm $<50$ circumference are amenable to medical management, while large pseudoaneurysm $>50$ circumference without secondary signs of injury may undergo delayed repair. They suggested a novel risk score for grade III BTAI to identify high-risk lesions and to improve patient selection for urgent $v s$. delayed aortic repair. This score includes admission lactate $>4 \mathrm{~mm}$, pseudoaneurysm/normal aortic diameter ratio $>1.4$ and mediastinal hematoma thickness along the descending thoracic aorta $>10 \mathrm{~mm}$ when almost two factors are contemporary present, the lesion is considered at high-risk for rupture. ${ }^{54}$ Further studies are needed to find out other independent predictors of early aortic rupture in grade III BTAI patients.

SVS GRADE IV

Grade IV BTAI necessitates emergency procedures and carries high mortality that may run up to $88.40,50$ Steuer et al. reported their experience in 17 cases of complete traumatic aortic transection. ${ }^{55}$.Most of them were involved in high-energy trauma (mainly car accidents of fallen from highs) and, consequently, the immediate mortality outcome (24) resulted highly dependent on the severity of other concurrent injuries, namely brain trauma and multiorgan failure.

\section{Timing of repair}

The correct timing for BTAI treatment is another discussed issue that requires further study to draw any definitive conclusion. At the beginning of the TEVAR experience for BTAI treatment, the American Association for the Surgery of Trauma (AAST) reported the results of a multicenter study. About 9 of mostly hemodynamically stable patients at in-hospital admission progressed to free rupture within 24 hours. This led to immediate treatment of BTAI as standard of care for many years. ${ }^{10}$ Urgent repair $(<24 \mathrm{~h})$ for BTAI is currently recommended from the SVS guidelines, published in 2011.43 Over the years, recommendations have been changed, shifting from urgent repair for all cases to NOM or delayed repair for patients with the lower grade of BTAI (I and II). The EAST (Eastern Association for the Surgery of Trauma) guidelines, based on a comprehensive review of the literature up to 2015 , concluded that delayed repair could be suggested for BTAI. ${ }^{34}$ However, there remains a need to adequately define whether specific risk factors associated with BTAI represent a higher risk for early aortic rupture and so requiring an emergent repair. Thanks to the help of selected panels of experts who continuously conduct reviews and meta-analysis of the literature, the International Societies of Vascular Surgery (ISVS) and the Trauma Foundations play a formidable role in providing information, defining appropriateness and addressing management of some particular issues of BTAI treatment. Their efforts are crucial in the development and updating of the current surgical management strategies for BTAI. In this regard, the Aortic Trauma Foundation (ATF), on behalf of the American Association for the Surgery of Trauma, in 2016 has started a prospective multicenter observational registry collecting data from 34 centers in 5 countries. Primary aim of this registry was to establish an aggregate database of information regarding clinical presentation, diagnosis, man- 
agement (acute and definitive), surveillance and outcomes following BTAI. Secondary aims were to examine predictors of early rupture ( $<24$ hours) and to examine outcomes following NOM of grade I-II BTAI.

\section{Devices for TEVAR in BTAI patients}

The first case report of successful TEVAR for BTAI was described in literature in 1997,33 but its use has been offlabel for many years. Only 15 years later FDA approved the first device with specific indication for use for traumatic transection. History and evolution of TEVAR for BTAI has been marked by important landmarks:

- 2005 FDA approval of Gore ${ }^{\circledR}$ TAG $^{\circledR}$ (Gore, Flagstaff, AZ, USA) for thoracic aneurysm repair. The initial capability of this device limited TEVAR application to patients with minimum aortic diameters of $23 \mathrm{~mm}$;

- 2008 FDA approval for thoracic aneurysm repair of smaller diameters devices Talent ${ }^{\circledR}$ (Medtronic, Santa Rosa, CA, USA) TX $2^{\circledR}$ (Cook Medical, Bloomington, IN, USA);

- January 2012 FDA approval for Conformable Gore ${ }^{\circledR}$ $\mathrm{TAG}^{\circledR}$ (Gore, Flagstaff, AZ, USA) for BTAI treatment;

- October 2012 FDA approval for Valiant ${ }^{\mathrm{TM}}$ (Medtronic, Santa Rosa, CA, USA) thoracic stent graft with Captivia ${ }^{\mathrm{TM}}$ delivery system for BTAI;

- November 2018 FDA approval of Valiant ${ }^{\mathrm{TM}}$ Navion Thoracic Stent Graft System (Medtronic, Santa Rosa, CA, USA) for BTAI.

None of these devices have a defined and clear indication for use in pediatrics population $(<18$ years). Currently, the C-TAG and Valiant ${ }^{\mathrm{TM}}$ endograft are available in 21 - and $22-\mathrm{mm}$ configurations and are indicated to treat down to 16- and 18-mm-diameter aortas, respectively. At these diameters, these two devices are available in lengths of 100 $\mathrm{mm}$ and $112 \mathrm{~mm}$, respectively, which requires a relatively larger proportion of coverage of the descending thoracic aorta. Besides, during the last years, manufactures have developed devices with lower-profile delivery system. Actually, Both Valiant ${ }^{\mathrm{TM}}$ Navion and Gore ${ }^{\circledR} \mathrm{C}^{-\mathrm{TAG}^{\circledR}}{ }^{\circledR}$ use 18 Fr sheath for delivery the stent grafts.

Considerations for treating BTAI in young patients must also take into account allowance for somatic growth. Some centers advocate the use of covered balloon-expandable stents because they are shorter in length and can be further dilated in the future as the patient's aorta grows. ${ }^{56}$

GORE $^{\circledR}$ C-TAG ${ }^{\circledR}$

The Gore ${ }^{\circledR} T A^{\circledR}$ thoracic endoprosthesis was the first endovascular thoracic aortic stent graft approved by the FDA in 2005 (Figure 3A-C). In 2012 its evolution, the C-
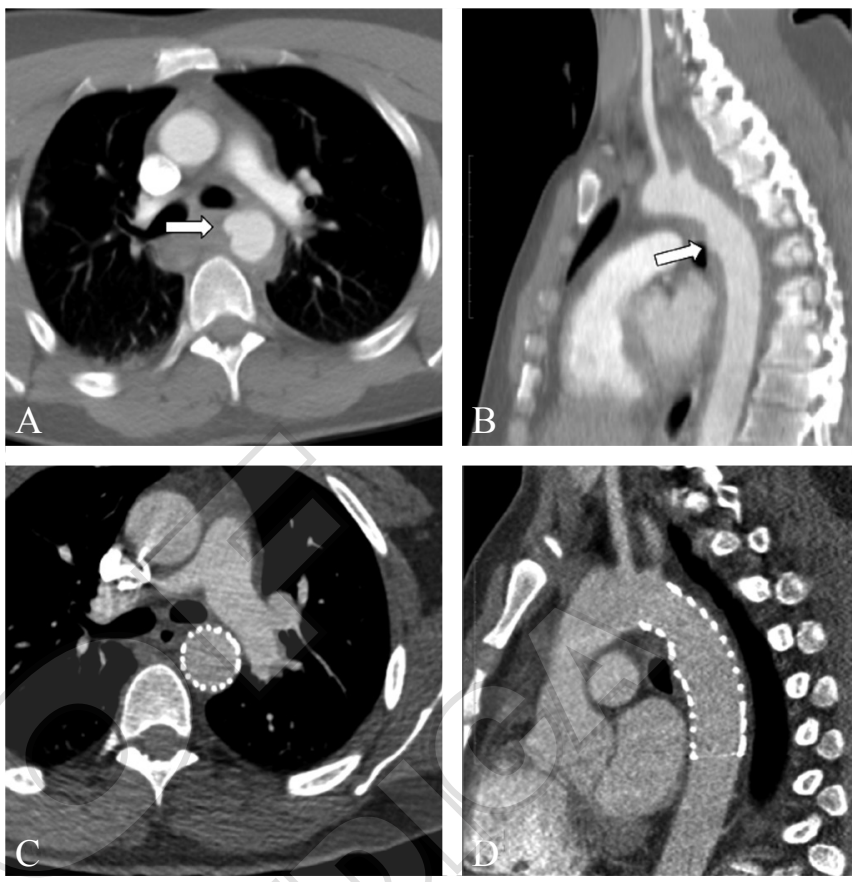

Figure 3.-Computed tomographic angiography (CTA) of BTAI grade III (SVS Classification) after fall from height. A) Preoperative, axial section of the pseudoaneurysm (arrow); B) preoperative, sagittal section of the pseudoaneurysm (arrow); C) postoperative control after deployment of 26-26 mm $10 \mathrm{~cm}$ length GORE ${ }^{\circledR}$ TAG $^{\circledR}$ Conformable Thoracic Stent Graft with active control. Resolution of pseudoaneurysm, axial section; D) postoperative control, sagittal section.

*BTAI: Blunt traumatic aortic injury; SVS: Society of Vascular Surgery

TAG device was the first FDA-approved device for use in BTAI. C-TAG device is made of expanded polyfluoroethylene (ePTFE), which is externally supported by a self-expanding Nitinol stent. The endograft is available in diameters from 21 to $45 \mathrm{~mm}$ and 10,15 and $20 \mathrm{~cm}$ lengths. C-TAG can be used in aortic necks with diameters ranging between 16 to $42 \mathrm{~mm}$, with a minimum proximal and distal seal zone length of $20 \mathrm{~mm}$. Moreover, also two measures of tapered devices are available as well as smaller diameters to treat aortas of younger trauma patients. The C-TAG device comes on a 100-cm delivery catheter constrained in an ePTFE outer sleeve that is laced up with a cord. The introducer sheaths have measures ranging from 20-27F. The graft is deployed by pulling the cord, which unlacing the covering sheath, allowing the Nitinol stent to expand to its design diameter. Graft deployment start rapidly from the middle of the graft outwards towards both ends. The new generation of devices, the Conformable $\mathrm{C}$ TAG, allow to conform better to the aortic arch curvature, avoiding graft collapse, lack of appositions and type I endoleak development. ${ }^{57}$ 
Medtronic Valiant and Navion

The Valiant ${ }^{\mathrm{TM}}$ thoracic stent graft with the Captivia ${ }^{\mathrm{TM}}$ delivery system is specifically designed for TEVAR (Figure 4). All stent graft components are composed of a selfexpanding, spring scaffold made from Nitinol wire sewn to a high-density woven monofilament polyester fabric graft with non-resorbable sutures. The Valiant ${ }^{\mathrm{TM}}$ thoracic stent graft is available in four configuration options freeflo straight (proximal component), closed web straight (distal component), distal bare spring straight (distal component), and closed web tapered (distal component). The first three configurations are available in diameters ranging from 22 $\mathrm{mm}$ to $46 \mathrm{~mm}$ and covered lengths of approximately 100 $\mathrm{mm}, 150 \mathrm{~mm}$, and $200 \mathrm{~mm}$. The closed web tapered stent grafts are available in proximal end diameters ranging from 26 to $46 \mathrm{~mm}$ and distal end diameters ranging from 22 to $42 \mathrm{~mm}$. The covered length is approximately $150 \mathrm{~mm}$. The proximal end of the closed web tapered configuration is 4 $\mathrm{mm}$ larger in diameter than its distal end. A closed web configuration should never be used as the most proximally implanted stent graft. The Captivia ${ }^{\mathrm{TM}}$ delivery system has a 22 F shaft. The RESCUE trial, a prospective, nonrandomized,
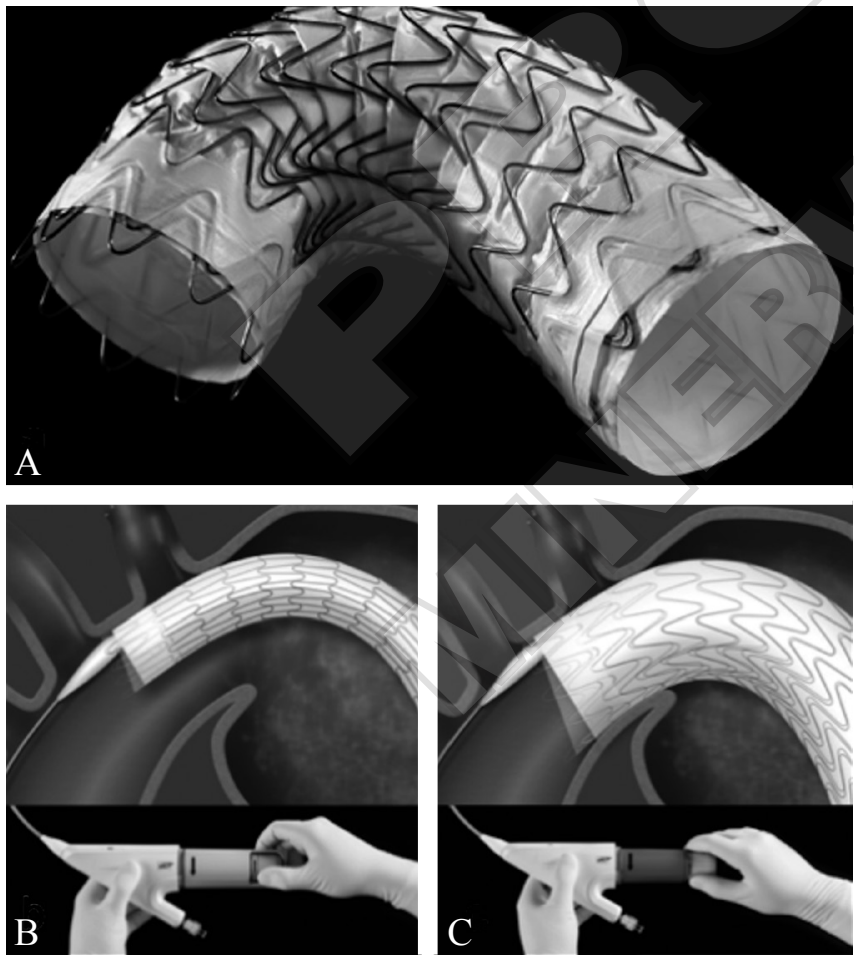

Figure 4.-Conformable C-TAG Gore endograft. A) The stent graft; B, C) the mechanism of deployment of the endograft and multicenter trial, was started in 2010 to evaluate the clinical performance of the Valiant ${ }^{\mathrm{TM}}$ thoracic stent graft for treatment of BTAI. The primary endpoint for this study was measured by the all-cause mortality rate within 30 days. The trial enrolled 50 patients at 20 USA and Canada investigational sites. The patients were all submitted to TEVAR within 1-day of injury with 35 (70.0) of aortic injuries of grade III BTAI or higher, including 1 free rupture and with a mean ISS of 37.6. Vascular access, device delivery, and deployment were successful in all patients with a median procedure time of 90.5 minutes. The left subclavian artery (LSA) was completely covered in 40 (20/50) and partially covered in $18(9 / 50)$ of patients. There were no postoperative strokes or spinal cord injuries. The 30-day all-cause mortality rate was $16.0(8)$ with an aorta-related mortality in 8.0 (4). The all-cause mortality rate within 1 year was 12 (6 cases) with an aorta-related mortality of 8 (4). During 1-year follow-up no type 1a endoleak was reported and no stent grafts kinking, twisting, fracture, or thrombosis were observed. ${ }^{58}$ Recently, Patel et al. reported the five-year follow-up analysis of the RESCUE trial. Of the 50 initial patients, most of them was grade III BTAI or worst and the extent of the lesions on the aortic arch needed complete or partial LSA coverage in 68 . Thirty-days mortality was 8 and 3 other patients died for non-aortic causes. Clinical and imaging compliance of the survivors were 90.3 and 67.7, respectively. No cases of stroke, spinal cord ischemia or endoleak were observed during the follow-up period. In 4 cases LSA revascularization was performed for the appearance of upper limb ischemia. No migration, kinking stent graft fractures or thrombosis were observed. ${ }^{59}$ In 2019 Medtronic presented the new Valiant ${ }^{\mathrm{TM}}$ Navion system, offering improvements thanks to the lower profile of $18 \mathrm{~F}$ ( $22 \mathrm{~F}$ for larger stent diameters) and the new design of the stent graft that offers better conformability. The new device is available in two proximal configurations FreeFlow and Covered Seal. It received also FDA approval for BTAI treatment.

Aortic Terumo Relay

The Aortic Terumo (formerly Bolton) Relay device is composed of self-expanding Nitinol stents with the proximal portion available with either a bare-metal stent or covered stent configuration (Figure 5,6). The stent graft is on a polyester graft. The device is available in $22-46 \mathrm{~mm}$ diameters, both in non-tapered and tapered configurations. The outer diameter of the delivery system ranges from 22 to $26 \mathrm{~F}$. It is the longest stent graft on the market (up to $25 \mathrm{~cm}$ ). However, this device is FDA approved only for aneurysm treatment. Zipfel et al. reported the experience 


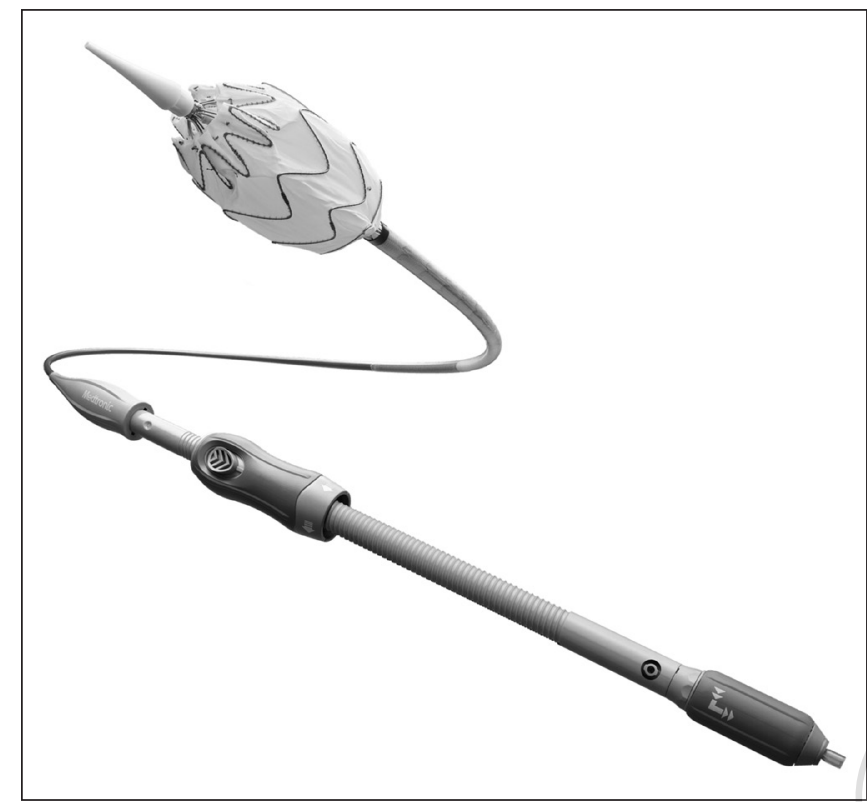

Figure 5.-Medtronic Navion endograft.

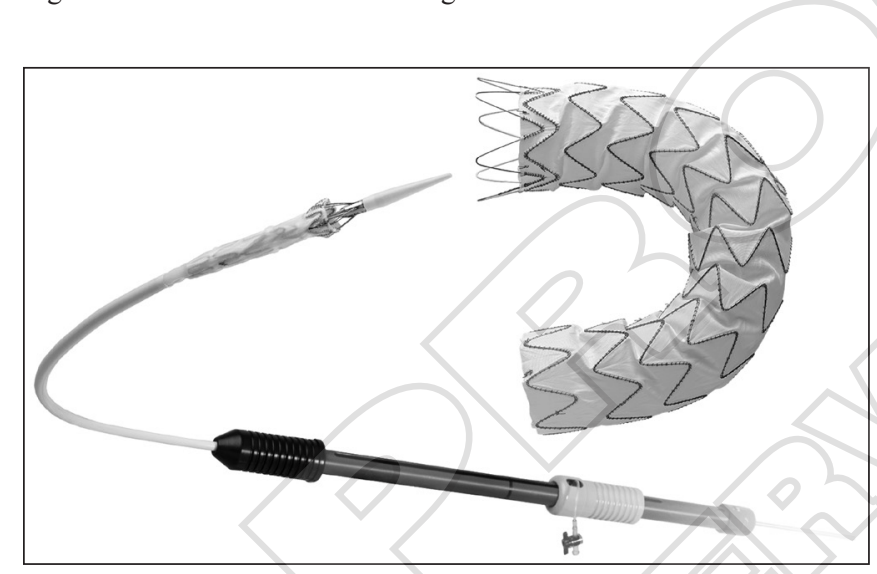

Figure 6.-Bolton Relay endograft.

of 12 European centers with the use of Relay endografts for BTAI. Forty adult patients, with an average age of 40 years, were treated by TEVAR with a technical success in all the cases, without any case of death, conversion to OR or paraplegia. Only 1 case (2.5) suffered from a rupture of the iliac artery, probably related to the size of the delivery system. The proximal landing zones were zones 1 or 2 in 40 of the cases and zone 3 in 55.60

\section{CoOK ZeNITH AlPhA}

Cook Medical products the Zenith Alpha Thoracic Endovascular Graft for TEVAR treatment in case of thoracic aorta disease. The Cook Zenith device is a modular system with proximal and distal components made of woven polyester attached to self-expanding steel Cook-Z stents. It is available straight or in tapered forms, and has barbs at the proximal and distal ends to help the fixation to the aortic wall. The Zenith Cook device is product in different size and length from 26 to $46 \mathrm{~mm}$ with different lengths from 105 to $233 \mathrm{~mm}$, respectively. Tsilimparis et al. reported the results of the SUMMIT study where, from 521 total TEVAR treatments using the Zenith platform, 50 cases regarded the treatment of BTAI. They reported excellent results in terms of mortality and stroke rates at 30 days and low aortic disease-related mortality during followup. ${ }^{61}$ The TRANSFIX study was started in 2015 recruiting 50 patients. ${ }^{62}$ Primary outcomes were 30 -day all-cause and aortic mortality rates, and any not graft-related death. Moreover, also 30-day technical success rate (successful access, deployment, and patency of the Zenith TX2 ${ }^{\circledR}$ Low Profile Endovascular Graft), and freedom from device collapse, type I or type III endoleaks requiring reintervention, and conversion to open surgical repair were considered as secondary outcomes. Authors reported initially good results, also in case of total percutaneous repair of BTAI. Unfortunately, FDA in 2017 notified a Class I recall, the most serious type of recall, specifically for the use of Zenith Alpha Thoracic endograft in case of BTAI treatment. This was because the use of this device could lead to thrombus formation inside after implantation. Moreover, it was also reported cases where the graft became blocked or closed when used to treat BTAI, causing serious injuries or death. Consequently, Cook initiated the correction of the instructions for use (IFU) for the Zenith Alpha Thoracic endograft, removing the indications for BTAI treatment. In particular the recall was for products in sizes of $18-22 \mathrm{~mm}$, including the 26-22 mm tapered device. In 2020, Starnes et al. updating the TRANSFIX results with 21-months follow up, reported the incidental finding of thrombus formation within the distal end of the device and extending into the native aorta. ${ }^{63}$ This complication was detected in 15 patients (30.0) although none of them, except for one that needed an additional aortic stent graft placement, had clinical sequelae. Thrombus resulted mainly located at the distal aspect of the device.

\section{Trauma center requirements for TEVAR treatment}

An open issue regards what level of trauma centers should perform TEVAR in case of BTAI. Trauma center levels across the nations are identified in different levels (i.e. level I, II, III, IV or V) and refer to the kind of resources available and the number of patients admitted yearly. 
Worldwide, a level I trauma center is capable of providing total care for every aspect of injury, TEVAR included. TEVAR could be performed successfully also in level II or III trauma centers. ${ }^{64}$ Using a standardized protocol with the TEVAR as first approach for BTAI, some multidisciplinary teams have reported excellent outcomes in low volume centers, similar to those of larger ones. ${ }^{65}, 66$ In fact, if the BTAI is handled properly, the outcome is closely influenced by the outcomes of the associated injuries. Even in more local, level IV trauma center have been reported excellent results in TEVAR of BTAI with outcomes strictly related to the severity of the aortic lesions. ${ }^{40}$ Another important issue regards the full availability of different sizes and lengths of TEVAR devices for BTAI in trauma centers. In a retrospective analysis performed on the CTA scan analysis of 35 patients with grade III BTAI, Rajani et al. reported that the range of proximal diameters ranged from 17 to $32 \mathrm{~mm}$, with an average aortic diameter of 23.9 $\mathrm{mm}$ and an average length, from the LSA to the proximal site of injury, of $16.2 \mathrm{~mm}$ (range 2-31 $\mathrm{mm}$ ). The average length of the injured aortic segment was $27 \mathrm{~mm}$ and most patients had $>15 \mathrm{~mm}$ landing zone beyond the LSA. According to these findings, authors concluded that BTAI patients usually have an aortic diameter that falls between 21 and $26 \mathrm{~mm}$, as well as a short segment of injured aorta. This allows to stock limited range of devices diameters and lengths for BTAI in trauma centers. ${ }^{67}$

\section{Management in polytrauma patients}

Major single traumatic lesions have improved their outcomes, gaining immediate survival in most of the cases. These results are obtained through the adoption of diagnostic and treatment protocols even if, nowadays, there is no worldwide consensus regarding priority of treatment in case of combined lesions and decision making is left in the hands of the trauma team. Diagnostic imaging provides precious information, identifying traumatic injuries, although delayed imaging may result in patient loss. Indeed, a huge debate is open about the correct timing and adoption of imaging techniques. The introduction of total-body CTA scan allows fast and complete screening of severely injured patients with blunt multiple traumas, thus helping to determine the priority of treatment. Associated injuries are rather common in BTAI especially head and major abdominal injuries. ${ }^{5}$ Currently, SVS guidelines suggest urgent repair only after stabilization of associated injuries. ${ }^{43}$ Rabin et al. reported association with traumatic brain injuries in 44 of BTAI. ${ }^{52}$ Early aortic repair within 24 hours of admission resulted independently associated with worsening post-traumatic brain injuries, irrespective from type of repair or perioperative anticoagulation. Urgent aortic repair was related with increased aortic morbidity and mortality in case of coexistence of brain traumatism. Another debated topic remains regards the opportunity to use full anticoagulation therapy in case of delayed intervention.

\section{Aortic sizing in BTAI}

Sizing of TEVAR devices is another discussed argument, in particular in the emerging setting. The BTAI population is usually composed of younger patients, without atherosclerosis and with an aortic wall more prone to dilatation under the gentle, but persistent, push of the outward radial force of the metallic stent graft. For these reasons, it is crucial to perform an accurate sizing of the preoperative aortic diameters in order to choose the right device. Often aortic sizing for BTAI is performed in conditions of hypotension and hypovolemia, and this could lead to underestimate the true aortic diameters choosing an undersized endograft with consequent risk of long-term development of type I endoleak and endograft migration. On the other side, the oversizing of the endograft could lead to the device infolding, collapse and, lastly, to graft failure. For all these reasons, devices with a wider range of operative diameters should be preferred because they could buffer the risks of endograft under- or oversizing. Alberta et al in a retrospective study on available diagnostic digital imaging for enrollment in two trials of the Gore ${ }^{\circledR}$ Conformable TAG $^{\circledR}$ thoracic device for the treatment of thoracic aneurysms and BTAI, observed differences between these cohorts that influence the choice of the device dimensions (e.g. CTAG device IFU recommend an oversizing window range from 6-33). In particular, Authors founded that all the aortic diameters increased 30-day after TEVAR, but the increases of the proximal and distal neck diameters were significantly greater in BTAI patients (12) than in aneurysm patients (6.9) $(3.0 \mathrm{~mm}$ vs. $2.0 \mathrm{~mm} ; \mathrm{P}<0.05$ for proximal zone and $2.9 \mathrm{~mm}$ vs. $0.7 \mathrm{~mm}$ for distal zone, respectively; $\mathrm{P}<0.01) .68$ Because of the increased aortic pulsatility compliance in younger patients, some Authors have proposed the use of Intravascular Ultrasound (IVUS) for intraoperative guidance. Wallace et al. measured the aortic diameters with IVUS in 22 patients and compared the obtained measures with sizing obtained by initial CTA. They reported significantly larger measures, because IVUS can provide more accurate measurements of the real aortic diameter during the cardiac cycle. ${ }^{69}$ 


\section{Left subclavian artery coverage}

Since the first TEVAR procedures for BTAI, one of the most debated issues was the need for coverage of the LSA, considering its supply to the left upper limb and homolateral vertebral artery, and its contribution to the collateral perfusion of the thoracic spinal cord. ${ }^{70}$ Rajani et al. analyzing CTA scan of 35 patients with traumatic transections of the thoracic aorta, reported that the average length from the LSA to the proximal site of injury was $16.2 \mathrm{~mm}$ (range $2-31 \mathrm{~mm}$ ) and that most of them had $>15 \mathrm{~mm}$ of landing zone beyond the LSA. The average length of the injured aortic segment was $27 \mathrm{~mm}$. They concluded that 91 of patients have anatomies treatable with a stent graft that does not need the coverage the LSA. ${ }^{67}$ On the other hand, some authors have not observed any difference on ability to return to usual activities after LSA coverage ${ }^{71}$ while others reported that it is not necessary and may increase the risk of spinal cord ischemic complications. ${ }^{72}$ Regarding the choice of an eventual LSA revascularization by extra anatomical carotid-subclavian bypass graft, this is associated with significantly higher rates of perioperative stroke and cardiopulmonary complications and so, in high-risk patients, endovascular LSA revascularization should be recommended over open surgery. ${ }^{73}$ LSA revascularization should be performed before TEVAR because it has lower perioperative complications if compared with post-TEVAR revascularization. ${ }^{73}$

\section{Long-term surveillance of TEVAR for BTAI}

Regular surveillance after TEVAR for degenerative thoracic aneurysm is needed as secondary interventions were required throughout the follow-up period. Postoperative surveillance by radiological imaging is usually performed by thoracic CTA performed at 1, 6 and 12 months postoperatively and yearly thereafter in order to detect the appearance of adverse post TEVAR-related complications, including endoleak, device migration and rupture. ${ }^{74}$ In case of BTAI, patients are usually younger and so need a longlife surveillance to control the impact of TEVAR on the degenerative changes that could place over the decades. However, considering that a patient could live for decades after the TEVAR treatment for BTAI, the amount of radiation could expose it to a cumulative radiation may be dangerous for malignancy development. ${ }^{75}$ Moreover, radiographic contrast media has other various long-term adverse effects such as contrast-induced nephropathy, allergic reactions and contrast-induced thyroid dysfunction. ${ }^{76}$ Rimon et al. evaluated in a case series of 7 patients without complications, yearly submitted to an average follow up period of 6.3 years with CTA scan. The average dose of radiation given to each patient resulted at least of $77 \mathrm{mSv}$, which resulted unnecessary, considering the stability and durability of modern TEVAR devices. Routinary yearly CTA should be avoided after the initial years of follow-up..$^{77}$ Alternative imaging such as magnetic resonance angiography (MRA) or time-of-flight MRI could be taken in consideration for long-term postoperative surveillance protocols in order to reduce radiation and contrast media administration. ${ }^{78}$

\section{Complications}

According to the various studies previously reported, TEVAR for BTAI presents a lower incidence of the typical complications that can occur after the other thoracic aortic degenerative pathologies treated by means of the endovascular approach. This is related to the fact that the deployment of the endograft usually occurs in a health thoracic aorta, without any sign of atherosclerotic degeneration. So, the endograft results more stable and complications, such as migration, endograft kinking or endoleaks, occur much less frequently. To confirm this, several studies reported that TEVAR treatment of BTAI is not associated with reintervention. $79-81$ Instead, after BTAI as well as the usual adverse events, could happened some peculiar complications that constitute a uniqueness of the endovascular treatment option postimplant hypertension, cardiovascular remodeling, endograft infolding and collapse, aortoesophageal fistula and stent-graft infection. ${ }^{82}$

POST IMPLANT CARDIOVASCULAR COMPLICATIONS

In young patients, TEVAR after BTAI may cause adverse cardiovascular complications due to increased aortic stiffness. Many patients develop arterial hypertension, ${ }^{83} \mathrm{LV}$ mass increase ${ }^{84}$ and experience and accelerated cardiovascular remodeling. Lower age and SCA coverage may contribute to the development of postimplant hypertension. Vallerio et al. ${ }^{85}$ hypothesized in the immediate postoperative period stent graft causes a sudden increase in aortic stiffness, producing an increase in BP values and triggering vascular remodeling, which is associated with fiber disarray. This latter, in turn, supports a stiffening mechanism which maintains the chronic increase in BP values. The alterations of the left ventricle can also be explained using the well-known physiological model of ventriculararterial coupling, according to which heart and vessels constitute an inseparable functional unit a stiffer aorta can determine a stiffer left ventricle, promoting its remodeling. Despite the great benefits that TEVAR has given in terms of short and long-term survival in patients with BTAI, we 
believe that is mandatory consider post implant cardiovascular complications in the younger population, with no particular comorbidity. The follow up of patients treated with TEVAR should include cardiological monitoring.

BIRD-BEAK, DEVICE INFOLDING AND COLLAPSE

The presence of an acute aortic arch angle and the narrow aortic diameter typical of young patients may lead to "bird beak" configuration after TEVAR. Bird-beak is defined as the presence of a gap between the aortic wall and the stent, with stent protrusion into the aortic lumen of more than 5 $\mathrm{mm}$ (Figure 7). ${ }^{86}$ The incomplete endograft apposition of the endograft is related to a higher risk of type-1 endoleak
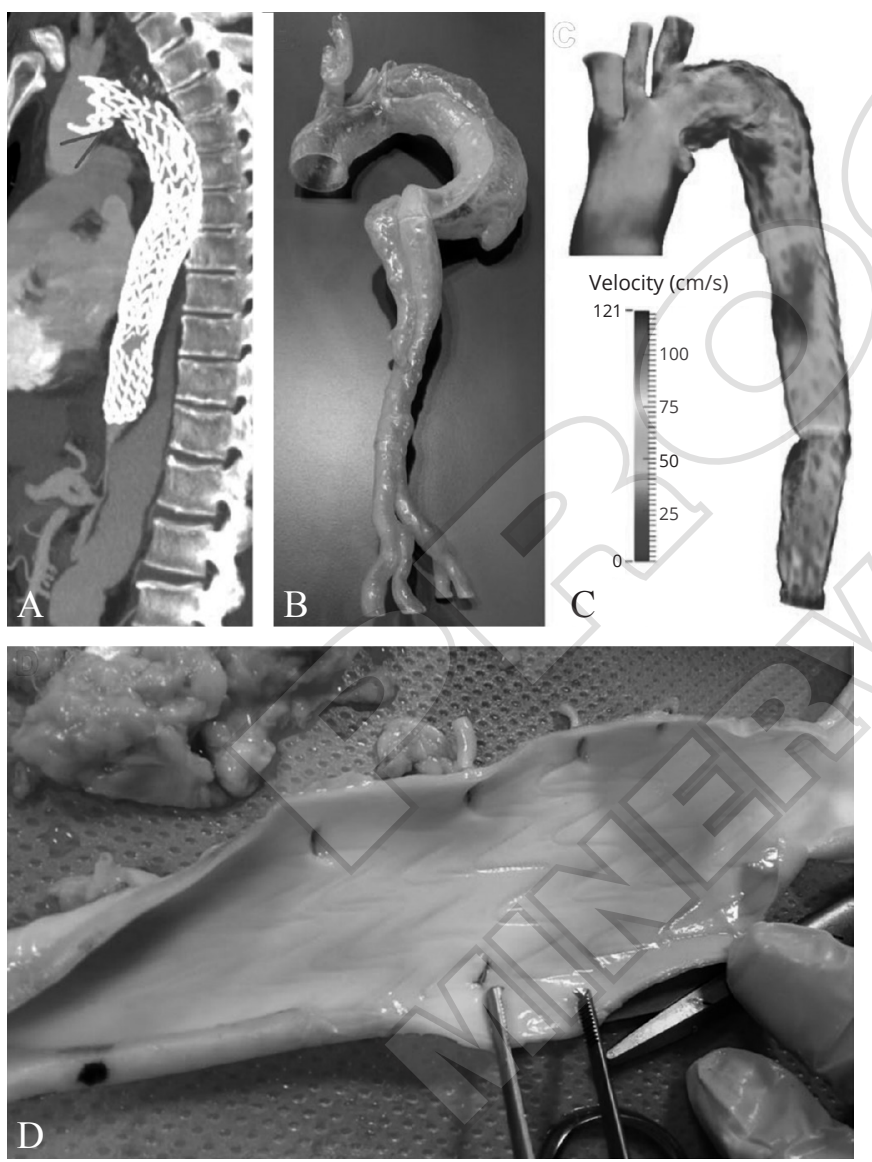

Figure 7.-A) Sagittal view of computed tomography imaging after thoracic endovascular aortic repair for type $\mathrm{B}$ aortic dissection, showing exclusion of the false lumen but poor stent-graft apposition with bird-beak formation; B) three-dimensional printed patient-specific model of a type B aortic dissection; C) computational fluid dynamics analysis demonstrating high velocity in the inlet and outlet of the 2 thoracic stent-grafts in a patient with chronic type B aortic dissection managed with thoracic endovascular aortic repair; D) superficial intima lesions after thoracic endovascular aortic repair in an ex vivo porcine model. From Nauta et al. ${ }^{86}$ formation. Garcia-Reyes et al. observed incomplete apposition of the device in the inner curve of the aortic arch in 65 of 64 patients submitted to TEVAR treatment for BTAI even if this finding was not significantly related to reintervention differently from what happen in case of TEVAR for degenerative thoracic aortic pathologies. ${ }^{87-89}$ In case of excessive oversizing of the endograft together with the above mentioned gothic aortic arch, the higher peak blood flow velocities and aortic wall elastic pulsatility, all these cofactors can result in the wrinkling of the proximal segment of the device and finally in infolding and collapse of the endograft. 22,90 Jonker et al. observed, in a review on the causes and timing of after TEVAR device collapse, that it happens more frequently in case of BTAI treatment (65). They reported 60 cases taken from the literature with an average time of 15 days after the intervention. The authors concluded that the small radius of the aortic curvature (48) and oversizing (20) were the main causes of device collapse. Thirty-day mortality resulted 8.3 and 3-years freedom from procedure-related mortality was 83.1 in asymptomatic and 72.7 in symptomatic patients, respectively $(\mathrm{p}<0.029) .{ }^{22}$ In case of severe infolding and collapse, it could be corrected by the percutaneous insertion of a supplemental bare X-large stent. ${ }^{91}$

AORTO-ESOPHAGEAL FISTULA

Another rare but serious after TEVAR complication is the development of an aorto-esophageal fistula (AEF). Eggebrecht et al. first described it in 2004 but the pathophysiological mechanism of its development remains still unclear. ${ }^{22}$ As possible causes, have been proposed several hypotheses: 1) direct erosion of the rigid endograft from the inner aorta to the outer esophagus; 2) esophageal necrosis secondary to the pressure exerted by the expansive push of the endograft; 3) esophageal necrosis secondary to thrombosis of side branches nutrient to the esophagus; and 4) direct stent-graft infection with extension and secondary erosion to the esophagus. In case of AEF a radical decision should be preferred to other option. A Redo-TEVAR could be proposed only in case of unstable patients as bridge intervention. Surgery essentially consists of esophagectomy, stent-graft removal and replacement of the aorta with silver-coated vascular prosthesis, rifampicin impregnated grafts, bovine pericardium or cryopreserved arterial homografts and, finally, with esophageal reconstruction.

\section{Conclusions}

TEVAR treatment for BTAI now can be considered the standard treatment but this does not mean that it is always 
the best and only choice. Discussions are still ongoing on many different issues such as requirements of the trauma center for TEVAR treatment, improvement of in hospital management, priority treatment in multi-trauma cases, classification system of BTAI and related treatment strategy, coverage of the left subclavian artery in short landing zone and spinal cord ischemia risk, lacks of device in pediatrics, cardiovascular remodeling, long life follow up and exposure to radiations, risk of infections, long-term durability of devices, management of endograft complications.

\section{References}

1. Sailer S. Dissecting aneurysm of the aorta. Arch Pathol (Chic) 1942;23. 2. Kuhn LP. Traumatic rupture of thoracic aorta with review of fifty-five abdominal injuries. Illinois MJ 1925;47:420.

3. Strassman G. Traumatic rupture of the aorta. Am Heart J 1947;33:508-15. 4. Parmley LF, Mattingly TW, Manion WC, Jahnke EJ Jr. Nonpenetrating traumatic injury of the aorta. Circulation 1958;17:1086-101.

5. Neschis DG, Scalea TM, Flinn WR, Griffith BP. Blunt aortic injury. N Engl J Med 2008;359:1708-16.

6. Dyer DS, Moore EE, Ilke DN, McIntyre RC, Bernstein SM, Durham $\mathrm{JD}$, et al. Thoracic aortic injury: how predictive is mechanism and is chest computed tomography a reliable screening tool? A prospective study of 1,561 patients. J Trauma 2000;48:673-82, discussion 682-3.

7. Steenburg SD, Ravenel JG. Acute traumatic thoracic aortic injuries: experience with 64-MDCT. AJR Am J Roentgenol 2008;191:1564-9.

8. Ungar TC, Wolf SJ, Haukoos JS, Dyer DS, Moore EE. Derivation of a clinical decision rule to exclude thoracic aortic imaging in patients with blunt chest trauma after motor vehicle collisions. J Trauma 2006;61:1150-5.

9. Mirvis SE, Shanmuganathan K, Buell J, Rodriguez A. Use of spira computed tomography for the assessment of blunt trauma patients with potential aortic injury. J Trauma 1998;45:922-30.

10. Fabian TC, Richardson JD, Croce MA, Smith JS Jr, Rodman G Jr, Kearney PA, et al. Prospective study of blunt aortic injury: Multicenter Trial of the American Association for the Surgery of Trauma. J Trauma 1997;42:374-80, discussion 380-3.

11. Burkhart HM, Gomez GA, Jacobson LE, Pless JE, Broadie TA. Fatal blunt aortic injuries: a review of 242 autopsy cases. J Trauma 2001;50:113-5.

12. Murad MH, Rizvi AZ, Malgor R, Carey J, Alkatib AA, Erwin PJ, et al. Comparative effectiveness of the treatments for thoracic aortic transection [corrected]. J Vasc Surg 2011;53:193-199.e1, 21.

13. Hoffer EK, Forauer AR, Silas AM, Gemery JM. Endovascular stentgraft or open surgical repair for blunt thoracic aortic trauma: systematic review. J Vasc Interv Radiol 2008;19:1153-64.

14. Takagi H, Kawai N, Umemoto $T$. A meta-analysis of comparative studies of endovascular versus open repair for blunt thoracic aortic injury. J Thorac Cardiovasc Surg 2008;135:1392-4.

15. Demetriades D, Velmahos GC, Scalea TM, Jurkovich GJ, KarmyJones R, Teixeira PG, et al.; American Association for the Surgery of Trauma Thoracic Aortic Injury Study Group. Operative repair or endovascular stent graft in blunt traumatic thoracic aortic injuries: results of an American Association for the Surgery of Trauma Multicenter Study. J Trauma 2008;64:561-70, discussion 570-1.

16. Baethge C, Goldbeck-Wood S, Mertens S. SANRA-a scale for the quality assessment of narrative review articles. Res Integr Peer Rev 2019;4:5.
17. Scale for the Assessment of Narrative Review Articles - SANRA. Deutsches Ärzteblatt; 2019 [Internet]. Available from: https://www.aerzteblatt.de/down.asp?id=22862 [cited 2020, Jul 29].

18. Green BN, Johnson CD, Adams A. Writing narrative literature reviews for peer-reviewed journals: secrets of the trade. J Chiropr Med 2006;5:101-17.

19. Moher D, Liberati A, Tetzlaff J, Altman DG; PRISMA Group. Preferred reporting items for systematic reviews and meta-analyses: the PRISMA statement. BMJ 2009;339:b2535.

20. Chung J, Owen R, Turnbull R, Chyczij H, Winkelaar G, Gibney N. Endovascular repair in traumatic thoracic aortic injuries: comparison with open surgical repair. J Vasc Interv Radiol 2008;19:479-86.

21. Estrera AL, Gochnour DC, Azizzadeh A, Miller CC 3rd, Coogan $\mathrm{S}$, Charlton-Ouw K, et al. Progress in the treatment of blunt thoracic aortic injury: 12-year single-institution experience. Ann Thorac Surg 2010;90:64-71.

22. Jonker FH, Giacovelli JK, Muhs BE, Sosa JA, Indes JE. Trends and outcomes of endovascular and open treatment for traumatic thoracic aortic injury. J Vasc Surg 2010;51:565-71.

23. Riesenman PJ, Brooks JD, Farber MA. Acute blunt traumatic injury to the descending thoracic aorta. J Vasc Surg 2012;56:1274-80.

24. Azizzadeh A, Charlton-Ouw KM, Chen Z, Rahbar MH, Estrera AL, Amer $\mathrm{H}$, et al. An outcome analysis of endovascular versus open repair of blunt traumatic aortic injuries. J Vasc Surg 2013;57:108-14, discussion 115 .

25. Chen SW, Wang SY, Liao CH, Huang YK, Liu KS, Lin PJ, et al. Timing of Intervention in Blunt Traumatic Aortic Injury Patients: Open Surgical versus Endovascular Repair. Ann Vasc Surg 2015;29:1559-66.

26. Grigorian A, Spencer D, Donayre C, Nahmias J, Schubl S, Gabriel $\mathrm{V}$, et al. National Trends of Thoracic Endovascular Aortic Repair Versus Open Repair in Blunt Thoracic Aortic Injury. Ann Vasc Surg 2018;52:72-8.

27. Calvo RY, Bansal V, Dunne CE, Badiee J, Sise CB, Sise MJ. A population-based analysis of outcomes after repair of thoracic aortic emergencies in trauma. J Surg Res 2018;231:352-60.

28. Elkbuli A, Dowd B, Spano PJ 2nd, Smith Z, Flores R, McKenney M, et al. Thoracic Endovascular Aortic Repair Versus Open Repair: Analysis of the National Trauma Data Bank. J Surg Res 2020;245:179-82.

29. Alarhayem AQ, Rasmussen TE, Farivar B, Lim S, Braverman M, Hardy $\mathrm{D}$, et al. Timing of repair of blunt thoracic aortic injuries in the thoracic endovascular aortic repair era. J Vasc Surg 2020;S0741-5214(20)31575-5.

30. Chiara O, Cimbanassi S, Zoia R. Injury to the Thoracic Aorta Following Fatal Blunt Trauma: An Autopsy Study. Eur J Trauma Emerg Surg 2009;35:305-10

31. Cowley RA, Turney SZ, Hankins JR, Rodriguez A, Attar S, Shankar BS. Rupture of thoracic aorta caused by blunt trauma. A fifteen-year experience. J Thorac Cardiovasc Surg 1990;100:652-60, discussion 660-1.

32. Demetriades D, Velmahos GC, Scalea TM, Jurkovich GJ, KarmyJones R, Teixeira PG, et al. Blunt traumatic thoracic aortic injuries: early or delayed repair - results of an American Association for the Surgery of Trauma prospective study. J Trauma 2009;66:967-73.

33. Kato N, Dake MD, Miller DC, Semba CP, Mitchell RS, Razavi MK, et al. Traumatic thoracic aortic aneurysm: treatment with endovascular stent-grafts. Radiology 1997;205:657-62.

34. Fox N, Schwartz D, Salazar JH, Haut ER, Dahm P, Black JH, et al. Evaluation and management of blunt traumatic aortic injury: a practice management guideline from the Eastern Association for the Surgery of Trauma. J Trauma Nurs 2015;22:99-110.

35. Khoynezhad A. Between a rock and a hard place? Not when dealing with traumatic aortic injuries! J Thorac Cardiovasc Surg 2015;150:1663.

36. Gavant ML. Helical CT grading of traumatic aortic injuries. Impact on clinical guidelines for medical and surgical management. Radiol Clin North Am 1999;37:553-74, vi.

37. Simeone A, Freitas M, Frankel HL. Management options in blunt aortic injury: a case series and literature review. Am Surg 2006;72:25-30. 
38. Azizzadeh A, Keyhani K, Miller CC 3rd, Coogan SM, Safi HJ, Estrera AL. Blunt traumatic aortic injury: initial experience with endovascular repair. J Vasc Surg 2009;49:1403-8.

39. Caffarelli AD, Mallidi HR, Maggio PM, Spain DA, Miller DC, Mitchell RS. Early outcomes of deliberate nonoperative management for blunt thoracic aortic injury in trauma. J Thorac Cardiovasc Surg 2010;140:598-605.

40. Lamarche $\mathrm{Y}$, Berger FH, Nicolaou S, Bilawich AM, Louis L, Inacio $\mathrm{JR}$, et al. Vancouver simplified grading system with computed tomographic angiography for blunt aortic injury. J Thorac Cardiovasc Surg 2012;144:347-54, 354.e1.

41. Starnes BW, Lundgren RS, Gunn M, Quade S, Hatsukami TS, Tran NT, et al. A new classification scheme for treating blunt aortic injury. J Vasc Surg 2012;55:47-54.

42. Rabin J, DuBose J, Sliker CW, O'Connor JV, Scalea TM, Griffith BP Parameters for successful nonoperative management of traumatic aortic injury. J Thorac Cardiovasc Surg 2014;147:143-9.

43. Lee WA, Matsumura JS, Mitchell RS, Farber MA, Greenberg RK, Azizzadeh A, et al. Endovascular repair of traumatic thoracic aortic injury: clinical practice guidelines of the Society for Vascular Surgery. J Vasc Surg 2011;53:187-92.

44. Heneghan RE, Aarabi S, Quiroga E, Gunn ML, Singh N, Starnes BW Call for a new classification system and treatment strategy in blunt aortic injury. J Vasc Surg 2016;64:171-6.

45. Riambau V, Böckler D, Brunkwall J, Cao P, Chiesa R, Coppi G, et al.; Esvs Guidelines Committee. Editor's Choice - Management of Descending Thoracic Aorta Diseases: Clinical Practice Guidelines of the European Society for Vascular Surgery (ESVS). Eur J Vasc Endovasc Surg 2017;53:4-52.

46. Kidane B, Parry NG, Forbes TL. Review of the management of blunt thoracic aortic injuries according to current treatment recommendations. Ann Vasc Surg 2013;27:1014-9.

47. Hayward R. VOMIT (victims of modern imaging technology) an acronym for our times. BMJ 2003;326:1273.

48. Fortuna GR Jr, Perlick A, DuBose JJ, Leake SS, Charlton-Ouw $\mathrm{KM}$, Miller CC 3rd, et al. Injury grade is a predictor of aortic-related death among patients with blunt thoracic aortic injury. J Vasc Surg 2016;63:1225-31.

49. Sandhu HK, Leonard SD, Perlick A, Saqib NU, Miller CC 3rd, Charlton-Ouw KM, et al. Determinants and outcomes of nonoperative management for blunt traumatic aortic injuries. J Vasc Surg 2018;67:389-98.

50. Soong TK, Wee IJ, Tseng FS, Syn N, Choong AM. A systematic review and meta-regression analysis of nonoperative management of blun traumatic thoracic aortic injury in 2897 patients. J Vasc Surg 2019;70:941953.e13.

51. Gaffey AC, Zhang J, Saka E, Quatromoni JG, Glaser J, Kim P, et al. Natural History of Nonoperative Management of Grade II Blunt Thoracic Aortic Injury. Ann Vasc Surg 2020;65:124-9.

52. Rabin J, Harris DG, Crews GA, Ho M, Taylor BS, Sarkar R, et al. Early aortic repair worsens concurrent traumatic brain injury. Ann Thorac Surg 2014;98:46-51, discussion 51-2.

53. Gandhi SS, Blas JV, Lee S, Eidt JF, Carsten CG 3rd. Nonoperative management of grade III blunt thoracic aortic injuries. J Vasc Surg 2016;64:1580-6

54. Harris DG, Rabin J, Kufera JA, Taylor BS, Sarkar R, O'Connor JV, et al. A new aortic injury score predicts early rupture more accurately than clinical assessment. J Vasc Surg 2015;61:332-8.

55. Steuer J, Wanhainen A, Thelin $S$, Nyman R, Eriksson MO, Björck M. Outcome of endovascular treatment of traumatic aortic transection. J Vasc Surg 2012;56:973-8.

56. Goldstein BH, Hirsch R, Zussman ME, Vincent JA, Torres AJ, Coulson $\mathrm{J}$, et al. Percutaneous balloon-expandable covered stent implantation for treatment of traumatic aortic injury in children and adolescents. Am J Cardiol 2012;110:1541-5.
57. Farber MA, Giglia JS, Starnes BW, Stevens SL, Holleman J, Chaer R, et al.; TAG 08-02 clinical trial investigators. Evaluation of the redesigned conformable GORE TAG thoracic endoprosthesis for traumatic aortic transection. J Vasc Surg 2013;58:651-8.

58. Khoynezhad A, Donayre CE, Azizzadeh A, White R; RESCUE investigators. One-year results of thoracic endovascular aortic repair for blunt thoracic aortic injury (RESCUE trial). J Thorac Cardiovasc Surg 2015;149:155-61.e4.

59. Patel HJ, Azizzadeh A, Matsumoto AH, Velazquez OC, Rovin JD, Lombardi JV, et al. Five-Year Outcomes From the United States Pivota Trial of Valiant Captivia Stent Graft for Blunt Aortic Injury. Ann Thorac Surg 2020;110:815-20.

60. Zipfel B, Chiesa R, Kahlberg A, Marone EM, Rousseau H, Kaskarelis I, et al.; RESTORE Investigators. Endovascular repair of traumatic thoracic aortic injury: final results from the relay endovascular registry for thoracic disease. Ann Thorac Surg 2014;97:774-80.

61. Tsilimparis N, Debus S, Chen M, Zhou Q, Seale MM, Kölbel T. Results from the Study to Assess Outcomes After Endovascular Repair for Multiple Thoracic Aortic Diseases (SUMMIT). J Vasc Surg 2018;68:1324-34.

62. Starnes BW, DwivediAJ, Giglia JS, Woo K, Yeh C, et al.; TRANSFIX Study Investigators. Endovascular repair for blunt thoracic aortic injury using the Zenith Alpha low-profile device. J Vasc Surg 2015;62:1495503.e1.

63. Starnes BW, Dwivedi A, Giglia J, Woo K, Yeh C; TRANSFIX Study Investigators. Updated outcomes from the TRANSFIX study to evaluate endovascular repair of blunt thoracic aortic injuries with the Zenith Alpha thoracic device. J Vasc Surg 2020;71:1851-7.

64. Asaid R, Boyce G, Atkinson N. Endovascular repair of acute traumatic aortic injury: experience of a level-1 trauma center. Ann Vasc Surg 2014;28:1391-5.

65. Powers WF 4th, Kane PN, Kotwall CA, Clancy TV, Hope WW. Endovascular repair of traumatic thoracic aortic injuries at a level II trauma center. Am Surg 2013;79:E91-2.

66. Steuer J, Björck M, Sonesson B, Resch T, Dias N, Hultgren R, et al. Editor's Choice - Durability of Endovascular Repair in Blunt Traumatic Thoracic Aortic Injury: Long-Term Outcome from Four Tertiary Referral Centers. Eur J Vasc Endovasc Surg 2015;50:460-5.

67. Rajani RR, Johnson LS, Brewer BL, Brewster LP, Duwayri Y, Reeves $\mathrm{JG}$, et al. Anatomic characteristics of aortic transection: centerline analysis to facilitate graft selection. Ann Vasc Surg 2014;28:433-6.

68. Alberta HB, Secor JL, Smits TC, Farber MA, Jordan WD, Azizzadeh A, et al. Comparison of thoracic aortic diameter changes after endograft placement in patients with traumatic and aneurysmal disease. J Vasc Surg 2014;59:1241-6

69. Wallace GA, Starnes BW, Hatsukami TS, Sobel M, Singh N, Tran NT. Intravascular ultrasound is a critical tool for accurate endograft sizing in the management of blunt thoracic aortic injury. J Vasc Surg 2015;61:630-5.

70. Malgor RD, Bilfinger TV. Left subclavian artery occlusion during blunt thoracic aortic injury endovascular repair. Ann Thorac Surg 2014;98:386

71. McBride CL, Dubose JJ, Miller CC 3rd, Perlick AP, Charlton-Ouw $\mathrm{KM}$, Estrera AL, et al. Intentional left subclavian artery coverage during thoracic endovascular aortic repair for traumatic aortic injury. J Vasc Surg 2015;61:73-9.

72. Celis RI, Park SC, Shukla AJ, Zenati MS, Chaer RA, Rhee RY, et al. Evolution of treatment for traumatic thoracic aortic injuries. J Vasc Surg 2012;56:74-80.

73. Delafontaine JL, Hu B, Tan TW, Tang GL, Starnes BW, Virk C, et al. Outcome Comparison of TEVAR with and without Left Subclavian Artery Revascularization from Analysis of Nationwide Inpatient Sample Database. Ann Vasc Surg 2019;58:174-9.

74. Grabenwöger M, Alfonso F, Bachet J, Bonser R, Czerny M, Eggebrecht $\mathrm{H}$, et al.; European Association for Cardio-Thoracic Surgery (EACTS); European Society of Cardiology (ESC); European Association 
of Percutaneous Cardiovascular Interventions (EAPCI). Thoracic Endovascular Aortic Repair (TEVAR) for the treatment of aortic diseases: a position statement from the European Association for Cardio-Thoracic Surgery (EACTS) and the European Society of Cardiology (ESC), in collaboration with the European Association of Percutaneous Cardiovascular Interventions (EAPCI). Eur J Cardiothorac Surg 2012;42:17-24.

75. Mettler FA Jr, Huda W, Yoshizumi TT, Mahesh M. Effective doses in radiology and diagnostic nuclear medicine: a catalog. Radiology 2008;248:254-63.

76. Singh J, Daftary A. Iodinated contrast media and their adverse reactions. J Nucl Med Technol 2008;36:69-74, quiz 76-7.

77. Rimon U, Shinfeld A, Gayer G. Traumatic injury of the thoracic aorta treated with stent-graft: is long-term CT angiography follow-up justified? Clin Radiol 2014;69:e207-10.

78. Pandey N, Litt HI. Surveillance Imaging Following Endovascular Aneurysm Repair. Semin Intervent Radiol 2015;32:239-48.

79. Martin C, Thony F, Rodiere M, Bouzat P, Lavagne P, Durand M, et al. Long-term results following emergency stent graft repair for traumatic rupture of the aortic isthmus. Eur J Cardiothorac Surg 2017;51:767-72.

80. Khoynezhad A, Azizzadeh A, Donayre CE, Matsumoto A, Velazquez $\mathrm{O}$, White R; RESCUE investigators. Results of a multicenter, prospective trial of thoracic endovascular aortic repair for blunt thoracic aortic injury (RESCUE trial). J Vasc Surg 2013;57:899-905.e1.

81. Mosquera VX, Marini M, Lopez-Perez JM, Muñiz-Garcia J, Herrera $\mathrm{JM}$, Cao I, et al. Role of conservative management in traumatic aortic injury: comparison of long-term results of conservative, surgical, and endovascular treatment. J Thorac Cardiovasc Surg 2011;142:614-21.

82. Miller LE. Potential long-term complications of endovascular stent grafting for blunt thoracic aortic injury. ScientificWorldJournal 2012;2012:897489.

83. Youssef A, Kalaja I, Alkomi U, Abt T, Hoffmann RT, Reeps C, et al. Aortic stiffness and related complications after endovascular repair of blunt thoracic aortic injury in young patients. Vasa 2020;49:295-300.
84. Kamenskiy A, Aylward P, Desyatova A, DeVries M, Wichman C, MacTaggart J. Endovascular Repair of Blunt Thoracic Aortic Trauma is Associated With Increased Left Ventricular Mass, Hypertension, and Offtarget Aortic Remodeling. Ann Surg 2020. [Epub ahead of print]

85. Vallerio P, Maloberti A, D’Alessio I, Lista A, Varrenti M, Castelnuovo S, et al. Cardiovascular Remodeling after Endovascular Treatment for Thoracic Aortic Injury. Ann Vasc Surg 2019;61:134-41.

86. Nauta FJ, Conti M, Kamman AV, van Bogerijen GH, Tolenaar JL, Auricchio F, et al. Biomechanical Changes After Thoracic Endovascular Aortic Repair in Type B Dissection: A Systematic Review. J Endovasc Ther 2015;22:918-33.

87. García Reyes ME, Gonçalves Martins G, Fernández Valenzuela V, Domínguez González JM, Maeso Lebrun J, Bellmunt Montoya S. LongTerm Outcomes of Thoracic Endovascular Aortic Repair Focused on Bird Beak and Oversizing in Blunt Traumatic Thoracic Aortic Injury. Ann Vasc Surg 2018;50:140-7.

88. Ueda T, Fleischmann D, Dake MD, Rubin GD, Sze DY. Incomplete endograft apposition to the aortic arch: bird-beak configuration increases risk of endoleak formation after thoracic endovascular aortic repair. Radiology 2010;255:645-52.

89. Wu IH, Liang PC, Huang SC, Chi NS, Lin FY, Wang SS. The significance of endograft geometry on the incidence of intraprosthetic thrombus deposits after abdominal endovascular grafting. Eur J Vasc Endovasc Surg 2009;38:741-7.

90. Tadros RO, Lipsitz EC, Chaer RA, Faries PL, Marin ML, Cho JS. A multicenter experience of the management of collapsed thoracic endografts. J Vasc Surg 2011;53:1217-22.

91. Sze DY, Mitchell RS, Miller DC, Fleischmann D, Frisoli JK, Kee ST, et al. Infolding and collapse of thoracic endoprostheses: manifestations and treatment options. J Thorac Cardiovasc Surg 2009;138:324-33.

92. Eggebrecht $\mathrm{H}$, Baumgart $\mathrm{D}$, Radecke $\mathrm{K}$, von Birgelen $\mathrm{C}$, Treichel U, Herold $\mathrm{U}$, et al. Aortoesophageal fistula secondary to stent-graft repair of the thoracic aorta. J Endovasc Ther 2004;11:161-7.

Conflicts of interest.-The authors certify that there is no conflict of interest with any financial organization regarding the material discussed in the manuscript. Authors' contributions.-Ilenia D'Alessio, Maurizio Domanin, Pierantonio Rimoldi, Bruno Palmieri and Gabriele Piffaretti have given substantial contributions to data analysis and collection, Ilenia D'Alessio, Maurizio Domanin and Daniele Bissacco to manuscript writing, Ilenia D'Alessio, Maurizio Domanin, Daniele Bissacco, Pierantonio Rimoldi, Bruno Palmieri, Gabriele Piffaretti and Santi Trimarchi to study design, manuscript revision and final approval. All authors read and approved the final version of the manuscript.

Acknowledgements.-The authors acknowledge Fulvia Domanin for the original drawings.

History.-Article first published online: - Manuscript accepted: September 18, 2020. - Manuscript received: August 17, 2020. 